\title{
自己排痰能力低下の予防に向けた 「咳嗽力アップ体操」の開発
}

\author{
Development of "Restorative Exercises for Cough Capacity" to Prevent Lowering of \\ Self-Expectorant Capacity
}

\author{
高石 直紀 ${ }^{1)} \quad$ 奥野 裕佳子 ${ }^{2)}$ 冨田 和秀 ${ }^{2)}$ \\ NAOKI TAKAISHI, RPT ${ }^{1)}$, YUKAKO OKUNO, RPT, $\mathrm{PhD}^{2)}$, KAZUHIDE TOMITA, RPT, $\mathrm{PhD}^{2)}$ \\ 1) Department of Rehabilitation, Konan Hospital: 48-1 Nagatsuka, Shimotsuma-shi, Ibaraki 304-0056, Japan \\ TEL+81296-44-2556E-mail: sou_futa@yahoo.co.jp \\ ${ }^{2)}$ Department of Physical Therapy, Ibaraki Prefectural University of Health Sciences
}

Rigakuryoho Kagaku 31(6): 851-856, 2016. Submitted May 24, 2016. Accepted Jul. 29, 2016.

ABSTRACT: [Purpose] We developed "restorative exercises for cough capacity" that mainly focuses on trunk function. The purpose of this study was to evaluate the specificity of trunk muscle activities during the exercises. [Subjects and Methods] The subjects were 8 healthy volunteers. The exercises were performed while sitting in a chair, and consisted of three types of exercise: chest expansion exercise (four types), spinal extension exercise (seven types), and abdominal wall muscle facilitative exercise (seven types). Oxygen consumption, tidal volume, and electromyography of the abdominal muscles were measured during the exercises. [Results] For the whole exercise, the metabolic equivalent and tidal volume were $1.6 \pm 0.8$ METs and 1,338.0 $\pm 610.8 \mathrm{ml}$, respectively. Furthermore, the total time of active internal abdominal oblique muscle use was significantly greater than those of the other muscles. [Conclusion] The exercises have low exercise intensity and increased the activity of the internal oblique muscle taking part in expiration during voluntary cough. Therefore, this particular exercise program can be expected to enhance the cough capacity of the elderly.

Key words: cough capacity, restorative exercises for cough capacity, abdominal wall muscle

要旨：〔目的〕本研究は，我々が開発した「咳嗽力アップ体操」の筋活動特異性を検証する事を目的とした。〔対象と 方法」対象は健常者 8 名とした。咳嗽体操は約 20 分とし, 椅座位で胸郭拡張運動 4 種目, 脊柱可動性向上運動 7 種目, 腹壁筋群促通運動 7 種目とした。体操中の酸素摂取量と換気量, 筋電図を測定した。〔結果〕咳嗽体操の酸素摂取量 と換気量は体操全体で $1.6 \pm 0.8 \mathrm{METs}, 1,338.0 \pm 610.8 \mathrm{ml}$ であった. 体操中の筋活動時間は内腹斜筋が有意に多かっ た。〔結語〕当咳嗽体操は低負荷で，随意咳嗽時の呼出に関与する内腹斜筋の筋活動が顕著であったことから，高齢 者等の咳嗽能力を高める可能性が示唆された.

キ一ワード：咳嗽力，咳嗽力アップ体操，腹壁筋

\footnotetext{
1) 湖南病院 リハビリテーション部：茨城県下妻市長塚 48-1 ( ₹ 304-0056) TEL 0296-44-2556

2) 茨城県立医療大学 理学療法学科

受付日 2016 年 5 月 24 日 受理日 2016 年 7 月 29 日
} 


\section{I. はじめに}

高齢者は加齢に伴い呼吸機能や咳嗽能力が低下し，誤 鱟性肺炎等の発症率も高くなる ${ }^{1)}$. 肺炎は悪性新生物や 脳血管疾患等と並び高齢者の死因として上位に挙げられ ており2), 重症化すれば生命予後に直結することが多い. 高齢入院患者では排痰能力の低下に伴い, 咳嗽時の最大 呼気流量（cough peak flow, 以下 CPF）が有意に低下 していたとの報告 ${ }^{3)}$ があり，随意的な咳嗽力が自己排 痰能力に必要であることが知られている。咳嗽は高い呼 気流速によって, 気道内の異物や分泌物を排出するため の重要な生体防御機能のひとつであり, その発生機序は 4 相からなる4). 吸気相では吸気筋群によって肺気量を 増加させ, 胸郭と腹壁が同時に拡張する。圧縮相では声 門を閉鎖し, 呼気性の肋間筋群, 腹筋群, 補助呼気筋群 の収縮により胸腔内圧が急激に上昇する。そして排除相 では，横隔膜の弛緩とともに声門が開き，さらに呼気筋 群の強い収縮によって呼気が起こるとされる。したがっ て, 咳嗽能力の低下はこれらの機序に何らかの問題が生 じることで起こることが推測される.

円背姿勢を有する高齢者では，正常群に比べ吸気筋力 と呼気筋力が有意に低下したとの報告がある ${ }^{5)}$. 円背姿 勢では骨盤後傾及び腰椎後弯角増大に伴うマルアライメ ントにより, 脊柱の伸展性や胸郭の拡張性が低下する ${ }^{6}$. 加えて脊柱後弯変形に伴う腹壁笳群および横隔膜の弛緩 に伴い, 筋の長さ - 張力曲線の関係により発生張力が減 少し，呼吸筋作用が低下するとの報告もある7)。した がって，これらの報告により，高齢者の咳嗽能力が低下 する要因として, 吸気相と排除相では, 加齢に伴う姿勢 の偏倚や脊柱・胸郭の可動性低下, 吸気筋および呼気筋 群の筋力低下などが影響することが推察される。また, 圧縮相は爆発的な呼気力を発生させるための準備期であ り, 各呼吸筋間の協調性や筋出力の夕イミングが重要で あるが, 高齢者では圧縮相の形成が不十分であることが 報告されている ${ }^{8)}$. 高齢者の呼吸機能は一旦低下すると 回復に難渋するため, 未然に防ぐあるいは遅らせるため の予防的介入が必要であるが, 自己排痰能力の低下予防 に特化した介入報告は少ない.

そこで我々は, 高齢者の咳嗽時呼出力を高めるために は, 脊柱や胸郭の可動性を改善すること, 補助呼気筋で ある腹壁筋群を強化すること, 吸気相 - 圧縮相一排除相 をタイミング良く行えるようにすることの仮説のもとに 「咳嗽力アップ体操（以下，咳嗽体操）」を試案した。当 体操は，深呼吸に伴った胸郭拡張と脊柱伸展，随意咳嗽 や呼気に合わせた体幹筋を促す運動とした。特に，体幹 筋の運動では, 咳嗽の圧縮相に関与する側腹筋（内腹斜 筋・腹横筋）の筋活動を促すものを取り入れた。また, 高齢者でも安全に実施できる運動強度になるように考案 した。
本研究では, 体操中の換気量や基礎代謝量, 体幹筋の 筋活動を測定し，考案した体操が換気量増加，側腹筋の 筋活動増大, そして低負荷の運動強度となっているかを 検証することを目的とした。

\section{II. 対象と方法}

\section{1. 対象}

本研究は, 茨城県立医療大学倫理委員会の承認を得て 行った。対象は, 本研究の趣旨に同意の得られた健常者 8 名（男性 7 名, 女性 1 名: 平均年齢 $21.1 \pm 2.4$ 歳）と した。

\section{2. 方法}

本実験では，呼気ガス分析，表面筋電図を同時に用い た。呼気ガスは, 呼気ガス分析装置（モバイルエアロモ ニタ AE-100i，ミナト医科学社製）を用い, breath by breath 方式で測定した。 また, 胸部ベルト型の心拍計を 同期させて記録した。表面筋電図 (Surface Electromyogram, sEMG）の記録には，表面筋電位計測 装置（P-EMG plus，追坂電子）を用いた（周波数帯域： $10 \sim 2,300 \mathrm{~Hz}$, 増幅率 : $1,000 \sim 5,000)$. 導出された信 号を AD 変換器 (PowerLab/16SP, AD Instruments 社製) を介してサンプリング周波数 $4 \mathrm{kHz}$ にてパーソナルコン ピューターに取り込み, 解析ソフト (LabChart7, AD Instruments 社製）を用いて波形解析を行った。表面電 極 $(38 \mathrm{~mm} \times 19 \mathrm{~mm})$ を右側の腹直筋と内腹斜筋, 最長 筋に貼付した，貼付部位は，臍上 $1 \mathrm{~cm}$ で正中より $2 \mathrm{~cm}$ 外側を腹直筋部 9), 左右の上前腸骨棘を結ぶ線の $2 \mathrm{~cm}$ 下方で鼡径勒帯の内側を内腹斜筋部 10), 第一腰椎棘突 起の $3 \mathrm{~cm}$ 外側を最長筋部 9) とし, 酒精綿で皮膚を前処 理した後, 筋線維に沿うように全て右側に貼付した。不 関電極は，右側の橈骨茥状突起部とした。その後，各表 面電極から筋活動に伴う sEMG 波形を確認した.

体操の内容および測定手順では, 体操の前に各筋群の 最大随意筋収縮（Maximal voluntary contraction, 以下 MVC）を測定した。その後対象者には背もたれのない 椅子に座らせ, フローセンサーと呼気ガス吸引ポートを 備えた筒型の器具を装着したフェイスマスクを取り付け た，対象者には，体操を正確に実施させるために，理学 療法士の指導者役が対面に座り, 体操の項目ごとに, デ モンストレーションを示しながら運動を誘導した。体操 はピラティスボール（ピラティスボール 200, トーエイ ライト社製）を使用した方法で，「胸郭の拡張を意識し た呼吸練習（以下，胸郭 Ex）」4 項目，「脊柱の可動性 を意識した運動 (以下, 脊柱 $\mathrm{Ex}$ )」 7 項目,「腹壁筋群 の促通を意識した運動（以下，腹壁 $\mathrm{Ex}$ )」 7 項目の計 18 項目とし，指導を含めて約 20 分間とした（図 1).

デー夕解析と統計処理については, 呼気ガス分析装置 


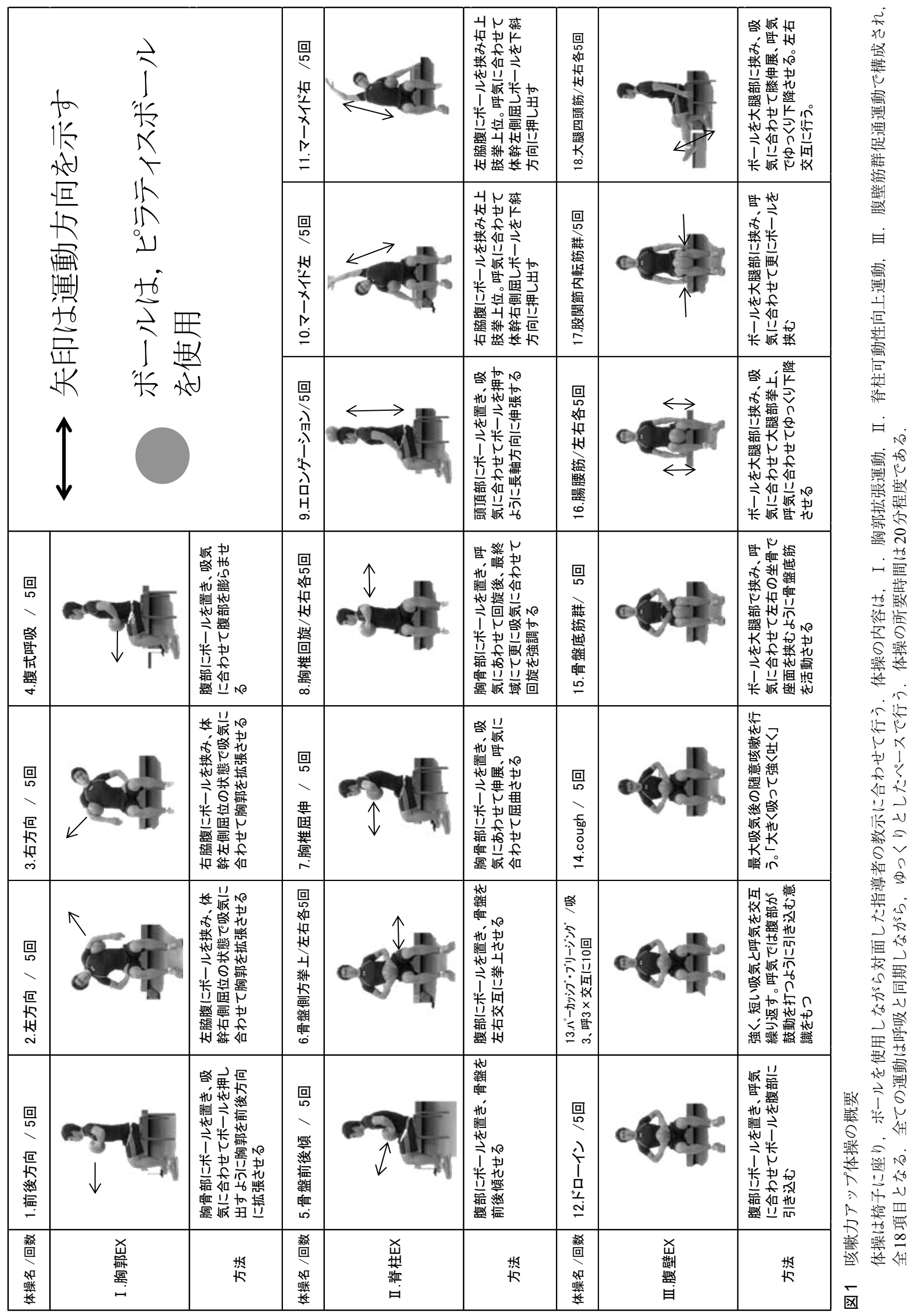




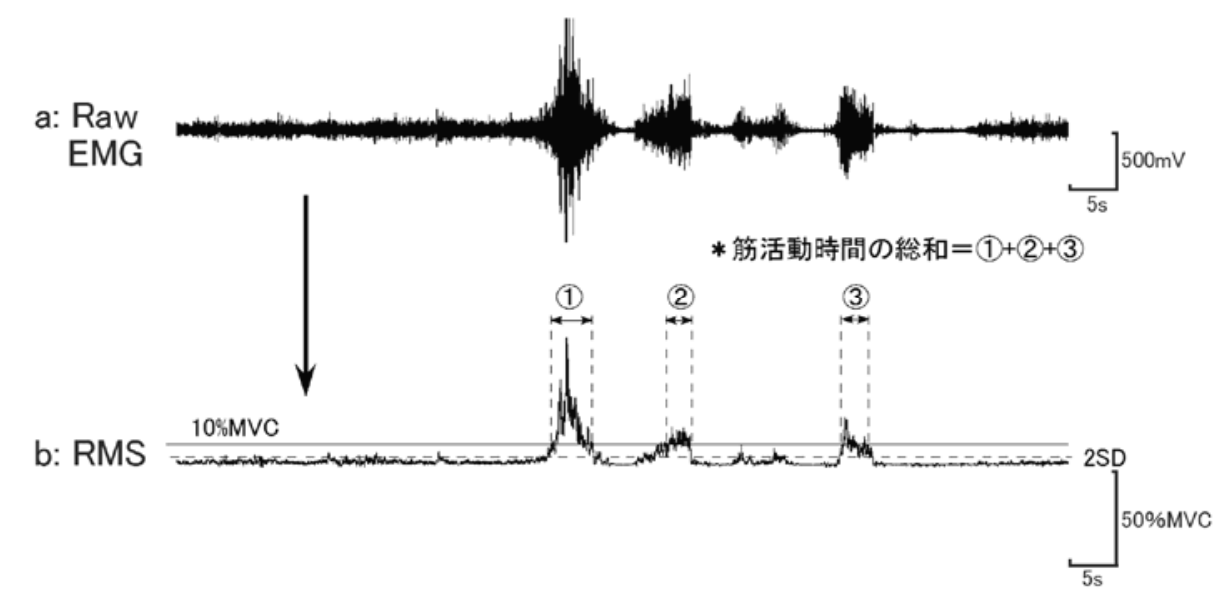

図2 筋活動時間の解析方法

a: Raw EMG：体操中に扔ける筋活動の筋電位原波形.

b: RMS:RMSにより波形を処理し, 各測定筋の最大随意筋収縮 (MVC)の百分率とした. $10 \% \mathrm{MVC}$ と $2 \mathrm{SD}$ の筋活動時間を算出した。

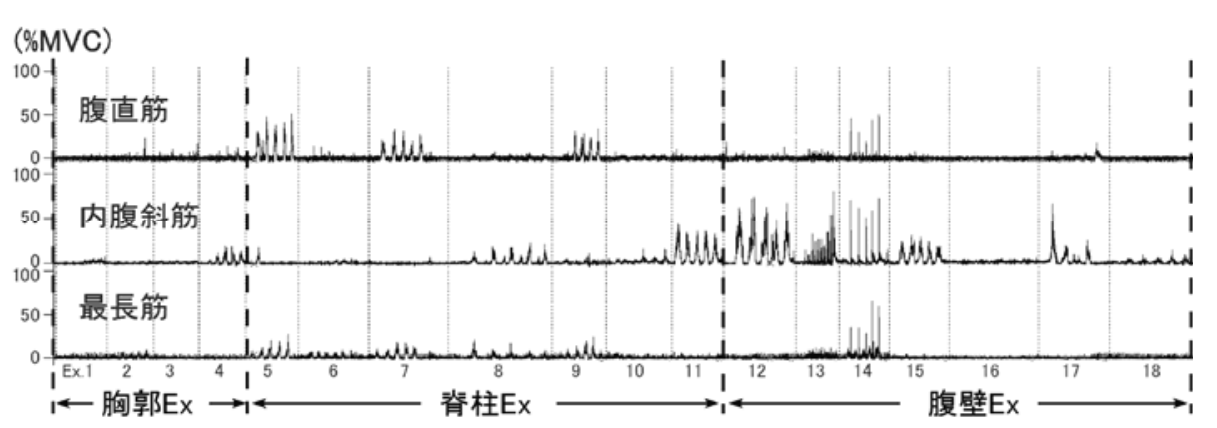

図3 体操中の筋活動 (代表例)

腹壁 $\mathrm{Ex}$ では内腹斜筋の活動が多く見られた，腹直筋，最長筋の活動は体操を通して少 なかった.

から得られた酸素摂取量と基礎代謝量（Metabolic equivalents, 以下 METs), 一回換気量, 心拍数 (Heart rate, HR）は, I : 胸郭 $\mathrm{Ex}, \mathrm{II}$ : 脊柱 $\mathrm{Ex}, \mathrm{III}$ ：腹壁 $\mathrm{Ex}$ 別の平均值と体操全体の平均值を算出した. $\mathrm{sEMG}$ 波形 は, 二乗平均平方根 (Root Mean Square, 以下 RMS) により整流平滑化し，各測定筋の最大随意収縮（MVC） の百分率を求めた（図 2). 表面電極を貼付した 3 つの 筋群ごとに, 安静時筋電位の平均值 $+2 \mathrm{SD}$ を超える筋活 動を示した時間の総和（以下, Time 2SD）を算出した. 同様に，10\% MVCを超える筋活動を示した時間の総和 （以下，Time 10\% MVC）も算出した（図 3). 統計学的 処理は各測定筋と体操フェーズを 2 要因とした反復測定 分散分析を行った。ささらに主効果が認められた要因に関 して多重比較 Bonferroni 法を行った。すべての解析は 統計解析ソフト（SPSS, ver.18）を用い, 有意水準を 5\% 未満とした。

\section{III. 結 果}

咳嗽体操中の換気量と呼気ガス分析の結果は表 1 に示 した。体操全フェーズでの基礎代謝量は $1.6 \pm 0.8$ METs であり，換気量は $1,338.0 \pm 610.8 \mathrm{ml}$ であった. また，心拍数は $77.5 \pm 5.8 \mathrm{bpm}$ であった（表 1 ). 各測 定項目と体操フェーズの関係について, 腹壁 $\mathrm{Ex}$ では基 礎代謝量で $1.8 \pm 0.9 \mathrm{METs}$, 心拍数では $78.7 \pm 5.3$ bpm と高值を示した。 なお, 脊柱 $\mathrm{Ex}$ では換気量が最も 高く, 1,419.7 $\pm 610.0 \mathrm{ml}$ であった（表 1$).$

体操全体の体幹筋の総活動時間は, Time 2SD で腹直 筋 $43.6 \pm 25.9$ 秒, 内腹斜筋 $333.6 \pm 188.7$ 秒, 最長筋 $98.3 \pm 73.1$ 秒であった（表 2 ). Time $10 \% \mathrm{MVC}$ では 腹直筋 $8.6 \pm 8.5$ 秒, 内腹斜筋 $103.5 \pm 85.3$ 秒, 最長筋 $2.6 \pm 3.6$ 秒であった（表 2). 各体操フェーズにおいて, Time 2SD, Time 10\% MVC のいずれも内腹斜筋の筋活 動時間が高值を示していた（表 2). 内腹斜筋の Time 2SD は, 胸郭 $\mathrm{Ex}: 35.6 \pm 29.9$ 秒, 脊柱 $\mathrm{Ex}: 147.4 \pm$ 
表 1 咳嗽体操中の呼吸機能

\begin{tabular}{|c|c|c|c|c|c|}
\hline & 安静時 & 胸郭 Ex & 脊柱 Ex & 腹壁 Ex & 体操全体 \\
\hline $\mathrm{VO}_{2}(\mathrm{~L})$ & $3.5 \pm 0.7$ & $4.7 \pm$ & $2.5 * \mathrm{~b}, \mathrm{~d}$ & $3.2 * \mathrm{c}, \mathrm{e}$ & $5.7 \pm$ \\
\hline METs & $1 \pm 0.2$ & $1.3 \pm$ & $0.7 * \mathrm{~b}, \mathrm{~d}$ & $0.9 * \mathrm{c}, \mathrm{e}$ & $1.6 \pm$ \\
\hline TV E (ml) & $469.3 \pm 91.2$ & $1,297.1 \pm 549.1 * \mathrm{a}$ & $1,419.7 \pm 610.0 * \mathrm{~b}$ & $1,295.0 \pm 606.2 * \mathrm{c}$ & $1,338.0 \pm 610.8$ \\
\hline HR (bpm) & $70.8 \pm 1.7$ & $75.1 \pm$ & $77.5 \pm 5.6$ & $78.7 \pm 5.3 * \mathrm{c}, \mathrm{e}$ & $77.5 \pm 5.8$ \\
\hline
\end{tabular}

平均值 \pm 標準偏差. $\mathrm{VO}_{2}$ : 酸素摂取量, METs : 代謝当量, $\mathrm{TV}$ : 一回換気量, $\mathrm{HR}$ : 心拍数, 体操全体 : 全体操 フェーズ. Bonferroni 法 $(*: \mathrm{p}<0.05$, a : 安静時 vs 胸郭 Ex, b : 安静時 vs 脊柱 Ex, c : 安静時 vs 腹壁 Ex, d : 胸 郭 $\mathrm{Ex} v \mathrm{~s}$ 脊柱 $\mathrm{Ex}, \mathrm{e}$ : 胸郭 $\mathrm{Ex}$ vs 腹壁 $\mathrm{Ex})$.

表 2 各体操フェーズにおける対象筋の筋活動時間

\begin{tabular}{lcccc}
\hline 対象筋 & 胸郭 $\mathrm{Ex}$ & 脊柱 $\mathrm{Ex}$ & 腹壁 $\mathrm{Ex}$ & 総活動時間 \\
\hline Time 2SD & & & & \\
$\quad$ 腹直筋 & $4.0 \pm 2.4$ & $19.8 \pm 14.0 * \mathrm{a}$ & $17.2 \pm 10.7 * \mathrm{~b}$ & $43.6 \pm 25.9$ \\
$\quad$ 内腹斜筋 & $35.6 \pm 29.9$ & $147.4 \pm 87.8 * \mathrm{a}, \mathrm{d}$ & $150.7 \pm 83.4 * \mathrm{~b}, \mathrm{~d}$ & $333.6 \pm 188.7$ \\
$\quad$ 最長筋 & $13.3 \pm 11.5$ & $43.0 \pm 38.9$ & $42.3 \pm 28.6 * \mathrm{~b}, \mathrm{e}$ & $98.3 \pm 73.1$ \\
Time $10 \% \mathrm{MVC}$ & & & & \\
$\quad$ 腹直筋 & $0.2 \pm 0.3$ & $5.8 \pm 8.2$ & $2.6 \pm 3.1$ & $8.6 \pm 8.5$ \\
$\quad$ 内腹斜筋 & $5.3 \pm 8.3$ & $42.6 \pm 43.8 * \mathrm{~d}$ & $55.6 \pm 35.2 * \mathrm{~b}, \mathrm{~d}$ & $103.5 \pm 85.3$ \\
$\quad$ 最長筋 & $0.0 \pm 0.0$ & $1.9 \pm 3.2$ & $0.6 \pm 0.8 * \mathrm{e}$ & $2.6 \pm 3.6$ \\
\hline
\end{tabular}

平均值 \pm 標準偏差. Time $2 \mathrm{SD}$ : 安静時筋電位の平均值 $+2 \mathrm{SD}$ を超える筋活動を示した時間の総和, Time 10\%MVC：10\%MVCを超えた筋活動を示した時間の総和.

Bonferroni 法 $\left(*: \mathrm{p}<0.05,{ }^{\mathrm{a}}\right.$ : 胸郭 $\mathrm{Ex} v \mathrm{vs}$ 脊柱 $\mathrm{Ex}, \mathrm{b}$ : 胸郭 $\mathrm{Ex} v \mathrm{vs}$ 腹壁 $\mathrm{Ex},{ }^{\mathrm{c}}$ : 脊柱 $\mathrm{Ex} v \mathrm{vs}$ 腹壁 $\mathrm{Ex}$, $\mathrm{d}$ : 腹直筋 vs 内腹斜筋, e : 腹直筋 vs 最長筋, $\mathrm{f}$ : 内腹斜筋 vs 最長筋).

87.8 秒，腹壁 $\mathrm{Ex} ： 150.7 \pm 83.4$ 秒となった。 Time $10 \%$ $\mathrm{MVC}$ では, 胸郭 $\mathrm{Ex}: 5.3 \pm 8.3$ 秒, 脊柱 $\mathrm{Ex}: 42.6 \pm$ 43.8 秒, 腹壁 $\mathrm{Ex}: 55.6 \pm 35.2$ 秒となった（表 2$)$. 腹 直筋の Time $2 \mathrm{SD}$ は, 胸郭 Ex : $4.0 \pm 2.4$ 秒, 脊柱 $\mathrm{Ex}$ : $19.8 \pm 14.0$ 秒, 腹壁 $\mathrm{Ex}: 17.2 \pm 10.7$ 秒であった（表 2 ). 最長筋の Time 2SD は, 胸郭 Ex : $13.3 \pm 11.5$ 秒, 春柱 $\mathrm{Ex}: 43.0 \pm 38.9$ 秒, 腹壁 $\mathrm{Ex}: 42.3 \pm 28.6$ 秒であった. Time 10\% MVCでは, 胸郭 Ex : 活動なし, 春柱 Ex : 1.9 \pm 3.2 秒, 腹壁 $\mathrm{Ex}: 0.6 \pm 0.8$ 秒であった（表 2 ). 反復 測定分散分析の結果, Time 2SD, Time 10\% MVC 共に 各筋群と体操フェーズにおいて主効果を認め, 交互作用 も有意であった。多重比較の結果, Time 2SD では腹直 筋と内腹斜筋の活動時間で, 胸郭 $\mathrm{Ex}$ と春柱 $\mathrm{Ex}$, 胸郭 $\mathrm{Ex}$ と腹壁 $\mathrm{Ex}$ で有意差を認めた。また, 最長筋の活動 時間では, 胸郭 $\mathrm{Ex}$ と腹壁 $\mathrm{Ex}$ で有意差を認めた（表 2). Time 10\% MVCでは, 内腹斜筋において胸郭 Ex と腹 壁 $\mathrm{Ex}$ で有意差を認めたが, 腹直筋と最長筋では有意差 はなかった（表2）。

\section{IV. 考 察}

咳嗽体操は椅座位にて行う全 18 項目から構成され, 所要時間は約 20 分であった。体操時の運動強度につい
ては, 体操全体で $1.6 \pm 0.8 \mathrm{METs}$ であり, 心拍数は $77.5 \pm 5.8 \mathrm{bpm}$ となった. 最も高值を示した体操フェー ズは腹壁 Ex で $1.8 \pm 0.9 \mathrm{METs}$ であった。身体活動時 の基礎代謝量については，これまでの報告より座位での 食事や入浴で $1.5 \mathrm{METs}$ を示し, セルフケア全般につい ても 2 METs 程度となっている 11). したがって当体操 は低負荷であり，椅座位にて適度に汗ばむ程度の負荷量 であるため，高齢者に対しても適応となることが想定さ れる，体操を生活の中で習慣化し，継続することも必要 であるため, 対象者にとって疲れない程度の適度な負荷 量設定は必要であると考える.

体操中の換気量は脊柱 Ex で高值を示し, 1,419.7 \pm $610 \mathrm{ml}$ であった。脊柱 $\mathrm{Ex}$ の構成は, 骨盤帯と脊柱の運 動を伴う内容であるが, 吸気時に脊柱を伸展させ, 呼気 時には屈曲させながら呼吸と運動を同期させている。横 隔膜は吸気時に腹腔内圧を上昇させ, 腹壁及び下部胸郭 を外方に拡張させる。ささらに横隔膜胁骨部の収縮により 下位胁骨を上方に持ち上げ，下部胸郭の直径を拡げる活 動をする 12). そのため, 加齢に伴う円背や脊柱の可動 制限により横隔膜の活動に伴う胸郭の拡張が妨げられ, 換気量が低下することも考えられる，春柱 Ex 時の換気 量増大については, 脊柱運動と呼吸の同期化によって横 隔膜の活動性が促通されたことも要因として挙げら 
れる。

体操中の筋活動特性では, 胸郭 $\mathrm{Ex}$ ・脊柱 $\mathrm{Ex}$ ・腹壁 $\mathrm{Ex}$ の全体操フェーズで内腹斜筋の活動が多く確認され たが，腹直筋・最長筋の活動は少なかった。そのため,

Time 2SD, Time 10\% MVCともに総活動時間でも同様

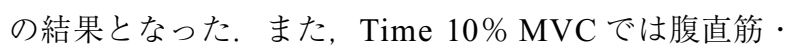
最長筋の活動はほぼ確認されなかったが, Time 2SD で は脊柱 $\mathrm{Ex}$ ・腹壁 $\mathrm{Ex}$ を中に最長筋の活動が確認され た。これらは座位運動時の姿勢保持筋としての活動が主 であり，脊柱運動時の主動作筋としての役割は少なかっ たことも考えられた。内腹斜筋は解剖学的に腹横筋との 融合があり，腹直筋や外腹斜筋の深層に位置している. 深層筋であるこれらの筋群は，体位の変換や維持におい て重要な役割を果たすが，呼息及び吸息時にも確認され る 12)。随意咳嗽時には前述したように，圧縮相から排 除相にかけて腹壁筋群の活動は重要である ${ }^{8)}$. Misuri ら 13) は最大呼気時に腹横筋と内腹斜筋の筋厚が増加し, 筋活動が高まったことを報告している，そのため，当体 操においても, 腹壁筋群の活動が高まる腹壁 Ex や脊柱 Exでの活動が顕著であったことが推察される.

結論として，当体操は低負荷であり，随意的咳嗽時の 呼出に関与する内腹斜筋の筋活動が顕著であったことか ら, 高齢者の自己排痰能力低下予防のための咳嗽能力を 高める可能性が示唆された。今後高齢者を対象とした介 入を進め, 介入による効果を検証していく必要がある.

\section{引用文献}

1) Teramoto S, Fukuchi Y, Sasaki H, et al.: High incidence of aspiration pneumonia in community and hospital-acquired pneumonia in hospitalized patients: A multicenter, prospective study in Japan. J Am Geriatr Soc, 2008, 56(3): 577-579.

2) 厚生労働省: 平成 27 年 (2015) 人口動態統計の年間推計. http://www.mhlw.go.jp/toukei/saikin/hw/jinkou/suikei15/ index.html.pdf(閲覽日 2015年 5 月 10 日).

3) 山川梨絵, 横山仁志, 渡邊陽介・他 : 排痰能力を判別する cough peak flowの水準一中高齢患者に抢ける検討一. 人工 呼吸, 2010, 27(2): 260-266.

4) Fishman AP, Mackiem PT, Mead J SR, et al.: Handbook of physiology: The respiratory system, Vol. III : Mechanics of breathing, part1, American Physiological Society, Maryland, 1986, pp315-336.

5) 伊藤弥生, 山田拓実, 武田 円：円背姿勢高齢者の呼吸 機能及び呼吸パターンの検討. 理学療法科学, 2007, 22(3): 353-358.

6) 武田広道, 岡山裕美, 大工谷新一: 骨盤, 脊柱アライメン トが胸郭可動性と呼吸機能に及ぼす影響. 理学療法科学, 2015, 30(2): 229-232.

7) 泉崎雅彦, 本間生夫：呼吸困難のメカニズム。呼吸と循環, 2003, 51(1): 57-65.

8) 朝戸裕子, 吉野克樹, 金野公郎：高齢者の咳嗽機能低下に 関する研究. 東京女子医科大学雑誌, 1997, 67(1,2): 49-54.

9) Tarnanen SP, Ylinen JJ, Siekkinen KM, et al.: Effect of isometric upper-extremity exercises on the activation of core stabilizing muscles. Arch Phys Med Rehabil, 2008, 89(3): 513-521.

10) White SG, McNair PJ: Abdominal and erector spinae muscle activity during gait: The use of cluster analysis to identify patterns of activity. Clin Biomech (Bristol, Avon), 2002, 17(3): 177-184.

11) Ainsworth BE, Haskell WL, Herrmann SD, et al.: 2011 compendium of physical activities: A second update of codes and MET values. Med Sci Sports Exerc, 2011, 43(8): $1575-1581$.

12) 山田拓実, 阿部 直：呼吸筋と姿勢制御筋一呼吸リハビリ テーションとの関係。呼吸と循環，2000, 48(3): 231-239.

13) Misuri G, Coladrande S, Gorini M, et al.: In vivo ultrasound assessment of respiratory function of abdominal muscles in normal subjects. Eur Repir J, 1997, 10(12): 2861-2867. 